\title{
TEACHING EXPERIMENTAL DESIGN METHODOLOGY USING TOYS AND SOFTWARE TOOLS
}

\author{
Leonard M. Lye, PEng, PhD, FCSCE, FEC \\ Professor and Chair of Civil Engineering \\ Faculty of Engineering and Applied Science, \\ Memorial University, St. John's, NL, A1B 3X5. \\ llye@mun.ca
}

\begin{abstract}
Most engineers do not have adequate training on how to deal with the design and analysis of multi-factored experiments. Yet, both ABET and CEAB clearly state that an engineering graduate should be able to conduct, analyse, and interpret the results of such experiments. It is now recognized that the factorial approach is the correct and scientific approach in conducting multi-factored experiments. The question is: how do we teach the proper experimental designs and principles to students in a course in such a way that is easy to learn, fun, exciting, competitive, and memorable? In this paper, an approach that uses specially designed toys and software that allow students to conduct multi-factored experiments, analyze the data collected, and do follow-up experiments, is described. Several physical and software toys are described and how they are used in a course on experimental design for engineers will be presented. The software used to analyze and present the data is also discussed.
\end{abstract}

\section{Introduction}

The design of engineering systems is rarely accomplished exclusively by applying fundamental scientific principles. In most cases, the design of systems also requires some use of empirical data and experimentation. As such, engineers, scientists, and even businesses carry out experiments in the field, laboratory, computer, or marketplace to discover how different factors may affect the response of the system they are investigating. Often these experiments are multi-factored with multi-responses. As usual, time and budget are limited. Most engineers when faced with such multi-factored problems often use the outdated one-factor-at-a-time approach. In fact most engineers, undergraduates or graduates, do not have adequate training on how to deal with the design and analysis of multi-factored experiments. Yet, both [1] and [5] clearly state that an engineering graduate should be able to conduct, analyse, and interpret the results of such experiments.

It is recognized that the factorial approach first introduced by R.A. Fisher is the correct and scientific approach in conducting multi-factored experiments. These designs are now widely used in industry. This is resulting in a trend of teaching engineers the design of experiments so they can more efficiently plan experiments and analyse and understand the results. These methodologies are now widely taught in industry through six sigma programs, as well as through more traditional college and professional education programs. The methods of experimental design are now widely disseminated and are having a significant impact throughout industry [6]. These designs are statistically based and should follow the basic statistical principles of experimental design. The question is: how do we teach all these designs and principles to students in a course in such a way that is easy to learn, fun, challenging, and memorable?

In this paper, an approach that uses specially designed toys and software that allow students to conduct multifactored experiments, analyze the data collected, and do follow-up experiments, is described. Several physical and software toys are described and how they are used in a course on experimental design for engineers will be presented. The software available to analyze and present the data is also discussed. It is hoped that these toys and tools will help facilitate the teaching and learning of proper design of experiment methodologies.

This paper has six sections. Section 2, the definition of an experiment will be given. A commonly used strategy and its pitfall for conducting experiments will be discussed in Section 3. In Section 4, teaching the key statistical concepts of design of experiments using 
specially designed toys will be presented. Strategies for using these toys and software to design the experiment, analyse the data collected, and present the results will also be discussed. Discussion and conclusion are given in Section 5. References are given in Section 6.

\section{Experiments}

An experiment is basically a test or a series of tests in which purposeful changes are made to the input variables or factors of a system so that we may observe and identify the reasons for changes observed in the outputs or responses [9].

In the field of engineering, many empirical equations in use today are the result of experiments carried out by researchers in the field, laboratory, or on computers using sophisticated computer models. As engineering systems and designs become more and more complex, to figure out the system response(s) as the many input factors are varied may be out of the question using analytical methods. One may have no choice but to resort to the experimental method.

Consider the design of an engineering system that has five input factors (A, B, C, D, and E) and two output responses $\left(\mathrm{Y}_{1}\right.$ and $\left.\mathrm{Y}_{2}\right)$. It may be desired to determine:

- the relative contribution of $\mathrm{A}, \mathrm{B}, \mathrm{C}, \mathrm{D}$, and $\mathrm{E}$ to the responses $Y_{1}$ and $Y_{2}$;

- which factors have a synergistic or antagonistic effect on the responses;

- $\quad$ an equation that can be used to predict $Y_{1}$ and $Y_{2}$ given values of the input factors; and

- what combination of the factors would maximize $\mathrm{Y}_{1}$ but minimize $\mathrm{Y}_{2}$ ?

As with most engineering problems, we are faced with limited time and budget. Hence we would like to gain as much information as possible and do so as efficiently as possible. How would one proceed to conduct such an experiment?

\section{Experimental Strategies}

In engineering, a prevalent method of experimentation in practice is the one-factor-at-a-time or OFAT approach. The OFAT method was once considered the standard, systematic, and accepted method of scientific experimentation. This method has been shown to be inefficient and in fact can be disastrous because it fails to take into account interaction effects [9]. This method of experimentation became outdated in the early 1920s when Ronald A. Fisher discovered much more efficient methods of experimentation based on factorial designs. This class of experimental designs includes the general factorial, two-level factorial, fractional factorial, and response surface designs among others. These statistically based experimental design methods are now simply called design of experiment methods or DOE methods. Some novel applications of DOE methods in engineering can be found in [8] and [10].

Basically, DOE is a methodology for systematically applying statistics to experimentation. DOE lets experimenters develop a mathematical model that predicts how input variables interact to create output variables or responses in a process or system. DOE can be used for a wide range of experiments in all fields of engineering and science. The use of statistics is important in DOE but not absolutely necessary. In general, by using DOE, we can:

- learn about the process we are investigating;

- screen important factors;

- determine whether factors interact;

- build a mathematical model for prediction; and

- optimize the response(s) if required.

DOE methods are also very useful as a strategy for building mechanistic models, and they have the additional advantage that no complicated calculations are needed to analyze the data produced from the designed experiment. It has been recognized for many years that the factorial-based DOE is the correct and the most efficient method of conducting multi-factored experiments; they allow a large number of factors to be investigated in few experimental runs. The efficiency stems from using settings of the independent factors that are completely uncorrelated with each other. That is, the experimental designs are orthogonal. The consequence of the orthogonal design is that the main effect of each experiment factor, and also the interactions between factors, can be estimated independent of the other effects. As stated earlier, industry has recognised this fact. Yet it is surprising that about 90 years after Fisher invented modern experimental design it is still not widely taught in schools of engineering in our universities. Surely an engineer who does not know how to run and design an efficient experiment is not a very good engineer. The question is: how do we teach all these statistically based designs and principles to students in a course in such a way that is easy to learn, fun, challenging, and memorable? 


\section{Toys and Software tools}

\subsection{DOE Toys}

Most of us are young at heart and not beyond playing with toys, especially toys that are fun, challenging, and educational. Hence using toys as a vehicle to teach design of experiment principles and methods is a good approach. In the literature, a number of toys have been suggested. Descriptions of some of these toys or apparatus are given below.

\section{Paper helicopter}

The use of paper helicopters have been described in great detail by [12]. For the paper helicopters, factors include length of wing span, weight added, height of drop, etc. The response would be the time before it hits the ground. Hence a paper helicopter can be designed to give the longest hang time. The paper airplane or helicopter experiments can be easily carried out in a class using only paper and scissors without requiring prior construction of the equipment.

\section{Ball through a funnel}

Another toy that has been discussed in the literature is the ball in a funnel experiment [9]. This toy would require the apparatus to be constructed. The construction details are given in Gunter's paper. The response studied in this experiment is the time for a ball or marble to spin through a funnel set at various heights. The ball or marble can be fed through a tube which can be varied by inclination and entry angle. Different types of balls can also be used. The funnel can be fastened so that it is somewhat loose which might have an interaction with the ball size. Many more factors can be studied. However, getting the experiment to work well depends very much on the relative sizes of the different components. To find an ideal combination of components that work well is an experiment by itself!

\section{Tabletop or floor hockey}

A toy that simulates the game of ice hockey called tabletop hockey which works quite well in the classroom is described in [2]. The template for the construction of such a toy is reproduced in Figure 1. The toy can be scaled up so that it can be played on a smooth floor. The objective of the hockey experiment is to learn how to shoot a puck for distance with a flexible, $15 \mathrm{~cm}$ ruler. The puck is comprised of two or more quarters (25-cent coins) stuck together with a gum adhesive. A simple wooden block acts as a fixture for the ruler. The response is the distance the puck slides over a smooth tabletop or floor surface. A more robust version that can be played on a smooth floor can be made using unbreakable Lexan ${ }^{\circledR}$ strip instead of a ruler, and pucks can be made out of a plastic material. Factors that can be studied include: stick length, windup distance, shot type, and puck weight. The circles in Figure 1 show the various locations for the factor named stick length. The marks below the line of the ruler relate to the factor named windup. The factor named shot type means that the puck can be slapped (slap shot) or can be flung forward (wrist shot). The puck weight can be changed by attaching washers or coins to the puck. A software version of the hockey toy called DOE-Hockey ${ }^{\mathrm{TM}}$ programmed in Java is also available for class demonstration. This is available from the author of this paper.

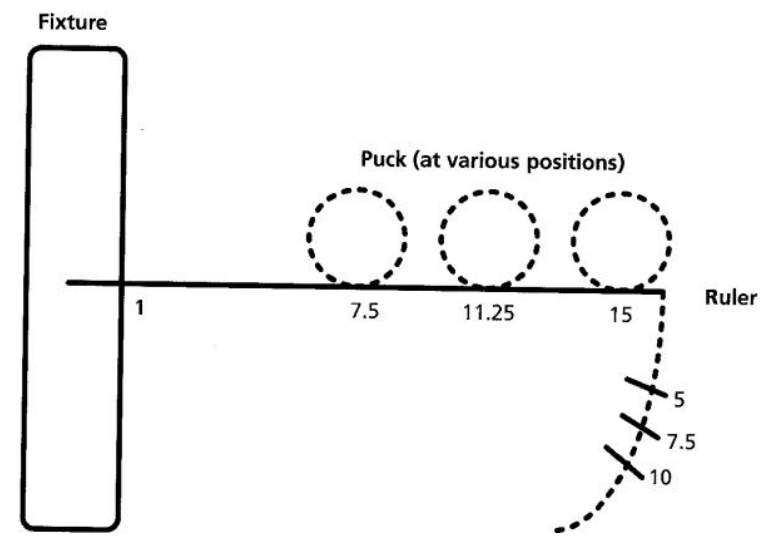

Figure 1: Template for tabletop hockey [2].

\section{Catapult or Statapult}

The catapult toy was first described in [11]. A commercial version of the catapult is the Statapult which is shown in Figure 2. Essentially the toy flings rubber balls instead of rocks. The catapult can be used to investigate several factors that will affect the distance travelled by the ball. At least six factors can be studied. These factors include: number of rubber bands used, height above the floor, angle of tilt of the catapult, pull back angle of the arm, stopping angle, position of the cup that holds the ball, and even the type of ball used. The response is the distance travelled by the ball. A second response could be the maximum height reached by the ball. One difficulty is to pin-point where the ball lands. 


\section{DOE-Golfer}

The DOE-Golfer ${ }^{\mathrm{TM}}$, invented by Com-Adv Devices Inc., is now used by many major corporations for sixsigma training. It is available from www.footworker.ca. Since golf is a universal game and many people know about the game, using golf as a vehicle to teach DOE would be very appealing to students. The golfing toy should have a wider appeal than tabletop hockey or the catapult. From experience in using these toys, the catapult appeals more to the younger students (first years) but not to older (engineers in professional development courses) students.

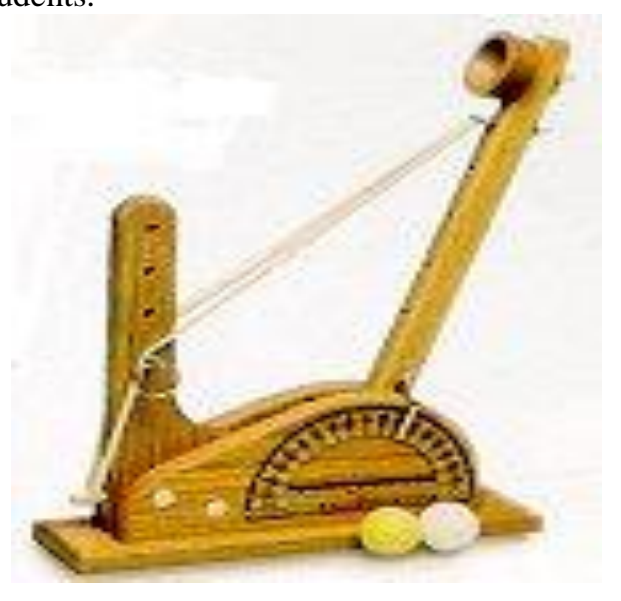

Figure 2: The Statapult

Tabletop hockey is generally appealing to Canadian students, but students from overseas and southern climates do not find it as fascinating. The DOEGolfer $^{\mathrm{TM}}$, however, seems to appeal to all students both young and old.

At least six factors can be studied with the DOEGolfer $^{\mathrm{TM}}$ : length of club, angle of swing, weight of club, type of ball, type of green or carpet, and direction. The first three are the major ones if only one type of ball is used and played on the same carpet, and if the floor and carpet are flat and uniform in all directions. Figure 3 shows the DOE-Golfer ${ }^{\mathrm{TM}}$. More details about the golfing toy can be found in [2] and at www.statease.com/golftoy.html. A software version of the DOE-Golfer programmed in Java is available from this author.

\subsection{How the toys are used}

It is best to use a group approach with groups of three, four, or five depending on the size of the class. Before the start of any formal lectures on DOE techniques, each group is assigned a toy. The group would first have to figure out how the toy work, the number of potential independent factors that can be varied, their possible levels, and the range of each factor. They also have to figure out the possible responses that can be measured and conditions to be held constant. Then they should consider their experimental strategy or strategies to figure out which of the factors has the greatest and least effect on the response, and whether any of the factors will interact with one another. It is quite normal that most students have not encountered the term interaction, much less what it means and how it can be measured. After a few doses of DOE techniques, the groups are asked to reconsider their original strategy. The groups will soon realize that using proper DOE techniques are definitely more effective. So each time a new technique is taught, for example, blocking, the groups will use the toys to carry out a blocking type experiment. The final topic is normally response surface methodology (RSM) and again the groups will use the toys to carry out various RSM designs. For example, with the catapult and DOE-Golfer $^{\mathrm{TM}}$, designs that can be carried out include: general factorial designs, two-level full factorial designs, fractional factorial designs, factorial designs with blocking, and various response surface designs.

A golf tournament can be played in a carpeted room using the DOE-Golfer ${ }^{\mathrm{TM}}$. Students can be divided into groups and given a week or two to train for the tournament. During this period, the groups can conduct the appropriate experiments and arm themselves with the equation(s) they need for the tournament. The tournament consists of two components: 1) Lines: masking tape can be placed on the carpet at three places along the North-South and East-West directions. The number of strokes to get to within $2 \mathrm{~cm}$ of each of the three lines is then totalled. 2) Holes: Four-hole golf challenge. Golf holes (drawn with chalk on the carpet) can be put at four places in the lounge and they have to get the ball in the holes. The group with the least total number of strokes is the winner.

It is best to let the groups choose the designs they will use for the tournament. Because it is a competition and the winning group gets bonus marks, most groups are very careful and secretive about their experiments. However, it is advisable to start with a simple twolevel experiment with the three main factors, and then check for curvature, and finally augment the two-level to a response surface design in which a face-centered central composite design or a Box-Behnken design can be used. 


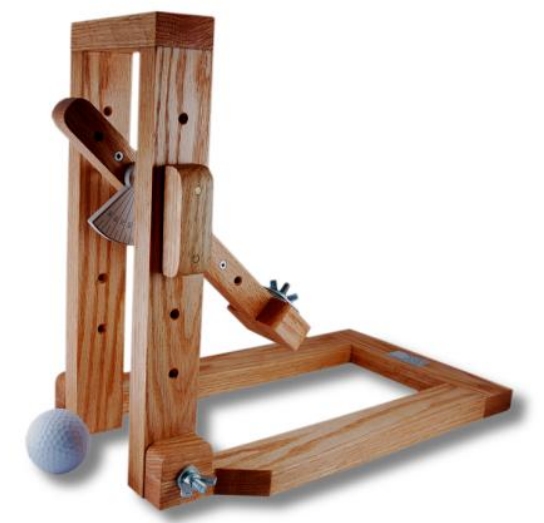

Figure 3: DOE-Golfer ${ }^{\mathrm{TM}}$

From past experience, groups that won the tournament clearly had the best design and were the most meticulous. They would notice that direction of travel of the ball is important. Going north to south is different from going south to north. Also, the eastwest direction is different from the north-south direction. Taking this into account would make quite a difference. The moral here is not to assume that the floor is flat or the carpet is uniform in all directions.

Using the DOE-Golfer ${ }^{\mathrm{TM}}$ as a vehicle for teaching DOE has been found to be a great success. The students really enjoyed it and they learned much about both DOE and golf and it was lots of fun. According to George Box "the best time to do an experiment is after it has been done", it is a good idea to ask the winners to share their secrets of their success and every group should be asked: If they had a chance to compete again, what would they do different? Most groups would probably agree that they should have done more replications and should have considered combinations that would give the shorter distances. For example, their first stroke would usually get them fairly close to the line or hole (maybe $3 \mathrm{~cm}$ away), and now they need a factor combination for $3 \mathrm{~cm}$. Some groups completely forgot about this possibility. Also, if they overshoot in the first stroke, the next stroke is in the opposite direction. If they did not consider direction as a factor, then again their prediction is not accurate.

\subsection{DOE Software}

The basic calculations required for designing and analysing factorial experiments are not difficult, Most of the calculations can be carried out by hand or by spreadsheet but can be tedious. Fortunately, aside from general software packages that have DOE routines e.g.
Minitab $^{\circledR}$, Systat ${ }^{\circledR}$, SAS $^{\circledR}$, among others, there exist quite a number of excellent standalone software packages designed specifically for DOE. A list of some of the DOE software available with a very brief description of their features is given below.

\section{Design-Expert}

This standalone software is available from Statease Inc. (www.statease.com). This easy to use software has all the major experimental designs (general ANOVA, two-level full and fractional factorials, three-level factorials, several RSM designs, mixture designs, and much more. More and more features are added with each new version of the software. It has powerful graphical tools and it has been featured in several well-known texts on DOE. Apparently it has been widely used in industry. The web site provides excellent DOE resources and one can download a 30day full version from the web site.

\section{DOE Wisdom}

This standalone software is available from Launsby Consulting (www.launsby.com). This software also claims that it offers practicality and ease-of-use that is ideal for beginners but with the computing power demanded by advanced users. It basically offers very similar features to Design-Expert with a few minor differences. One can download a 15-day full version of the software for the web site.

\section{DOEpack}

This standalone software available from PQ Systems (www.pqsystems.com) also features the usual classical and Taguchi designs with a wide selection of screening designs, process optimization design and analysis tools. It has good graphical tools and an intuitive user interface.

\section{$J M P$}

This standalone DOE software is developed by the well-known SAS Institute, developers of the SAS program. More information can be obtained from (www.jmp.com). This is also powerful software and provides design choices for almost every situation. Perhaps the additional feature that is not available in the other software is that the user can perform custom designs which give the experimenter the most flexibility. JMP also has space-filling designs for computer experiments. Obviously, these features are only useful for the expert user. Limited time free 
download of the software is also available from the JMP web site.

Aside from standalone software, there are also Excel add-in DOE software where the software runs within and is fully integrated with, Microsoft Excel spreadsheet package. Two such software are: $D O E$ PRO XL available from (www.sigmazone.com) and DOE KISS available from the DOES Institute (www.does.org). These software provide the familiar spreadsheet interface and basically have most of the features of the above standalone packages.

There is a wide choice of software and it is advisable to download the free trial versions and try them out. The final choice depends on price, features, and availability of technical support for the software itself and for statistical help, resources and advice.

\section{Discussion and Conclusion}

To meet accreditation requirements it is essential that all engineering programs include the teaching of proper design of experiments methodologies somewhere in their program. The sooner they are taught the better. Several physical and software versions of toys and how they can be used in a course in design of experiment methodology were described. Several software that can be used to analyse the data collected and present the results of the experimental design was also discussed. The use of specially designed toys as a vehicle for teaching and learning design of experiments has been a great success. It is hands-on, fun, challenging, and memorable. It is thus highly recommended.

\section{References}

[1] ABET (2008). Criteria for Accrediting Engineering Programs, Engineering Accreditation Commission, MD.

[2] Anderson, M. J. and Whitcomb, P. J. 2000. DOE Simplified: Practical Tools for Effective Experimentation, Productivity Inc. Portland, OR.

[3] Anderson, M. J. and Whitcomb, P. J. 2005. RSM Simplified: Optimizing Processes Using Response Surface Methods for Design of Experiments. Productivity Inc. Portland, OR.
[4] Box, G. E. P., W. G. Hunter, and J. S. Hunter (1978): Statistics for Experimenters: An Introduction to Design, Data Analysis, and Model Building, NY, Wiley Interscience.

[5] CEAB, 2008. Accreditation Criteria and Procedures, Engineers Canada.

[6] Dym, C. L., Agogino, A. M., Ozgur, E., Frey, D. D., and Leifer, L. J. 2005. Engineering Design Thinking, Teaching, and Learning, Journal of Engineering Education, Vol. 94, No. 1, pages 103-120.

[7] Gunter, B. 1993. Through a Funnel Slowly with Ball Bearing and Insight to Teach Experimental Design, The American Statistician, Vol. 47, November.

[8] Islam, M. F. and Lye, L. M. 2009. Combined Use of Dimensional Analysis and Modern Experimental Design Methodologies in Hydrodynamics Experiments, Ocean Engineering, 36, pp 237-247.

[9] Montgomery, D. G. 2009. Design and Analysis of Experiments, $7^{\text {th }}$ Edition, John Wiley and Sons, Inc.

[10] Mukhtasor and Lye, L. M. 2004. Use of Response Surface Methodology in Extracting a Model from an Artificial Neural Network: A Case of Initial Dilution Modelling, Proceedings of the $33^{\text {rd }}$ Annual Conference of the Canadian Society for Civil Engineering, Saskatoon, Saskatchewan, June.

[11] Schmidt, S.R. and Launsby, R. G. 1994. Understanding Industrial Designed Experiments, $4^{\text {th }}$ Edition, Air Academy Press, Colorado.

[12] Tiao, G. C., Hill, B., Bisgaard, S., Pena, D., and Stigler, S. (Editors), 2000. Box on Quality and Discovery: with Design Control, and Robustness. John Wiley and Sons, New Jersey. 